\title{
Evaluation of Antimicrobial and Antibiofilm Activities of Copper Oxide Nanoparticles within Soft Denture Liners against Oral Pathogens
}

\author{
Elham Ansarifard $\left(\mathbb{D},{ }^{1,2}\right.$ Zahra Zareshahrabadi $\mathbb{D}^{3},{ }^{3}$ Najmeh Sarafraz, ${ }^{4}$ \\ and Kamiar Zomorodian $\mathbb{1 D}^{3,5}$ \\ ${ }^{1}$ Department of Prosthodontics, School of Dentistry, Shiraz University of Medical Sciences, Shiraz, Iran \\ ${ }^{2}$ Nanobiology and Nanomedicine Research Center, Shiraz University of Medical Sciences, Shiraz, Iran \\ ${ }^{3}$ Department of Parasitology and Mycology, School of Medicine, Shiraz University of Medical Sciences, Shiraz, Iran \\ ${ }^{4}$ Department of Periodontology, School of Dentistry, Rafsanjan University of Medical Sciences, Rafsanjan, Iran \\ ${ }^{5}$ Basic Sciences in Infectious Diseases Research Center, Shiraz University of Medical Sciences, Shiraz, Iran
}

Correspondence should be addressed to Kamiar Zomorodian; zomorodian@sums.ac.ir

Received 13 March 2021; Revised 26 April 2021; Accepted 26 May 2021; Published 4 June 2021

Academic Editor: Guillermo Mendoza-Diaz

Copyright (c) 2021 Elham Ansarifard et al. This is an open access article distributed under the Creative Commons Attribution License, which permits unrestricted use, distribution, and reproduction in any medium, provided the original work is properly cited.

\begin{abstract}
Objectives. Soft denture liners provide a favorable environment for adhesion and colonization of microorganisms. This in vitro study aimed to examine the efficacy of different concentrations of copper oxide nanoparticles (CuO NPs) incorporation into soft denture liner on the biofilm formation of the microbial species. Methods. Field Emission Scanning Electron Microscopy (FESEM) images from NPs were recorded. Antifungal susceptibility testing of CuO NPs against five standard strains of Candida albicans (CBS 10261, 1905, 1912, 1949, 2730), Streptococcus mutans (ATCC35668), Streptococcus sobrinus (ATCC27607), and Streptococcus salivarius (ATCC9222) was performed by the broth microdilution method with the Clinical and Laboratory Standards Institute reference method. The biofilm inhibition percentages of $\mathrm{CuO}$ NPs on the soft denture liners were determined by XTT assay. Results. The characterization of $\mathrm{CuO}$ NPs by scanning electron microscope (SEM) analyses confirmed the synthesis of NPs with appropriate structure and size with a mean diameter of $18.3 \pm 9.1 \mathrm{~nm}$. The CuO NPs successfully inhibited the growth of the tested standard strains of C. albicans and Streptococcus spp. at concentrations ranging from 64 to $128 \mu \mathrm{g} \mathrm{mL}^{-1}$. Indeed, incorporation of $\mathrm{CuO}$ NPs at a concentration of $500 \mu \mathrm{g} \mathrm{mL}^{-1}$ into the soft denture liners exhibited a significant activity (75\%) in inhibition of C. albicans. biofilm formation in a dose-dependent manner. The biofilm formation of C. albicans in the presence of CuO NPs was lower than Streptococcus spp. in comparison with the control group $(p<0.05)$. Conclusion. Incorporation of CuO NPs significantly decreased the colonization and plaque formation of the oral pathogens, especially C. albicans accumulation. These NPs may be useful as a promising agent for the antimicrobial management of soft denture liner materials.
\end{abstract}

\section{Introduction}

Soft denture liners are resilient materials that are used as a shock absorber under the denture, to reduce the functional loads to the bearing mucosa by distributing the loads homogeneously on the denture-bearing tissues [1]. This is mainly useful in patients with sharp or atrophic ridges having a low tolerance to the loads applied by the dentures.
They are also commonly used for conditioning the irritated tissues mostly induced by ill-fitted dentures. Soft denture liners are prone to easy deterioration, which increases the surface roughness. It will result in an increase in susceptibility to colonization and growth of the microorganisms. Studies have shown that fungal and bacterial microorganisms initially adhere to the surface of the lining and accumulations on the appliances [2-4]. In the oral cavity, most 
colonizing and infecting microorganisms are found not as single-living cells, but rather as complex structured microbial communities, often encapsulated within a matrix of exopolymeric material, and attached to biotic or abiotic surfaces. These communities are referred to as biofilms $[5,6]$. Microbial biofilms are 3D structures that have gained the ability to resist antimicrobials and immune cell challenges. It is noteworthy that environmental conditions under the denture as well as the structure of materials supported this microbial growth and played a key role in denture-related stomatitis $[7,8]$. Denture stomatitis is a common disease in denture wearers (15-70\%) which mainly contributes to Candida spp. and oral bacteria $[6,9]$. On the other hand, for some elderly patients with some physical and mental disabilities, conventional chemical and mechanical denture cleansing procedures are challenging [10].

Moreover, some of the mentioned cleansing methods can also damage the soft denture liners and cause more microbial plaque accumulation $[11,12]$. Several researchers have already incorporated a variety of medicament including antifungal drugs, metal oxides, and herbs into the soft denture liners, as a reliable method to overcome dentureinduced stomatitis $[13,14]$. Although many of these modified soft denture liners showed promising results against microorganisms, different shortcomings were also reported for the investigated additives. For example, there was no certain durability and robustness of the effective dose for the evaluated additives. Some of these soft denture liners were reported to be effective only for a short time (3-7 days) $[4,15]$. Some other studies demonstrated that some of these antifungal additives compromise the mechanical properties of the soft denture liners [16, 17]. Although the beneficial effect of antimicrobial additives to the soft denture liners has been proved, no antimicrobial soft liner is commercially available, yet. Nanotechnology has numerous modern applications in the field of dentistry, including disease diagnosis, therapy, and prevention. Restorative dentistry, cancer diagnosis and treatment, implant dentistry, and molecular imaging are some examples of the application areas [18]. Nanomaterials are natural or manufactured materials containing particles in the size ranges of $1-100 \mathrm{~nm}$ [19]. Recently, copper oxide nanoparticles (CuO NPs) have been extensively used in different areas of science and technology due to their good thermal, electrical conductivity, and low cost [20]. Previous studies have demonstrated that the incorporation of NPs in orthodontic brackets and alginates significantly reduces the amount of microbial biofilm $[21,22]$. Recently, in order to reduce both the cost and the toxicity of $\mathrm{CuO}$ NPs, biological sources such as plants have been used instead of chemical methods, which have shown an additional antibacterial activity, as well [23-25].

To the best of our knowledge, there is still no report about the antimicrobial and antibiofilm activity of the $\mathrm{CuO}$ NPs incorporated into the soft liner in different concentrations. Therefore, this study aimed to evaluate the effectiveness of incorporating $\mathrm{CuO}$ NPs into the soft liner and assess its antimicrobial and antibiofilm activity effects against Streptococcus mutans, Streptococcus sobrinus, Streptococcus salivarius, and Candida albicans.

\section{Materials and Methods}

2.1. Synthesis and Characterization of $\mathrm{CuO}$ NPs. Briefly, $25 \mathrm{~mL}$ ethanolic solution of copper acetate (Merck, Germany, $0.2 \mathrm{~mol} \mathrm{~L}^{-1}$ ) was mixed with $25 \mathrm{~mL}$ ethanolic solution of sodium hydroxide (Merck, Germany, $0.4 \mathrm{~mol} \mathrm{~L}^{-1}$ ) by a magnetic stirrer followed by the addition of $0.5 \mathrm{~g}$ polyethylene glycol (molecular weight, 20,000) (Merck, Germany). The mixture was then refluxed for $25 \mathrm{~min}$. A brown precipitate was obtained that was washed several times by absolute ethanol and acetone. The sample (CuO NPs) was dried at room temperature. Besides, Field Emission Scanning Electron Microscopy (FESEM) images from $\mathrm{NP}_{\mathrm{S}}$ were recorded using a TESCAN Mira 3-XMU (Czech Republic).

2.2. Preparation of Resin Disks Containing Different Concentrations of $\mathrm{CuONPs}$. In this study, we used a self-cured acrylic-based soft liner (GC Cooperation, Tokyo, Japan) which consists of powder and liquid. According to the manufacturer's instructions, experimental soft denture liner discs $(10.0 \times 3.0 \mathrm{~mm})$ were fabricated containing $0,0.5,5,50$, and $500 \mu \mathrm{g} \mathrm{mL}^{-1}$ concentrations of $\mathrm{CuO}$ NPs. After $\mathrm{CuO}$ NPs incorporation, the prob sonication (soniprep-150, England) was used for 3 minutes to disperse the mixture. Afterward, the powder and liquid were mixed placed in a disk-shaped silicone mold, pressed between two glass slabs until the soft denture liner cured, and then polished. A total of 80 discs were prepared and divided into five groups $(n=16)$ according to the concentration of $\mathrm{CuO}$ NPs incorporated. Then, within a group, four soft denture liner discs were assigned to each strain.

2.3. Disinfection of the Specimens. The specimens were disinfected by immersing in glutaraldehyde $2 \%$ for $2 \mathrm{~min}$ and rinsed with sterile water.

2.4. Antimicrobial Susceptibility Tests. The antimicrobial activity of $\mathrm{CuO}$ NPs against five standard strains of Candida albicans (CBS 10261, 1905, 1912, 1949, 2730), Streptococcus mutans (ATCC35668), S. sobrinus (ATCC27607), and S. salivarius (ATCC9222) was determined. Standard strains of bacteria and C. albicans were seeded on the brain heart infusion agar and Sabouraud dextrose agar (Merck, Germany), respectively. Then, the culture plates were incubated at $35 \pm 2^{\circ} \mathrm{C}$ between 18 and $24 \mathrm{~h}$. Minimum inhibitory concentration (MIC) of CuO NPs against standard strains of bacteria and $C$. albicans was determined by the broth microdilution method as recommended by the clinical and laboratory standards institute (CLSI), in the range of $0.5 \mu \mathrm{g}$ $\mathrm{mL}^{-1}-512 \mu \mathrm{g} \mathrm{mL} L^{-1}$.

Briefly, RPMI-1640 medium (with L-glutamine and phenol red, without bicarbonate, Sigma, USA) was prepared and buffered at $\mathrm{pH} 7.0$ with $0.165 \mathrm{~mol} 3$-(N-morpholino) propane sulfonic acid (MOPS) (Sigma-Aldrich, Steinheim, Germany). Serial dilutions of NPs $\left(0.5\right.$ to $\left.512 \mu \mathrm{g} \mathrm{m}^{-1}\right)$ were prepared in 96-well microtitre trays using RPMI-1640 buffered with MOPS. Stock inoculums were prepared by 
suspending three colonies of the examined bacteria and C. albicans in $5 \mathrm{~mL}$ sterile $0.85 \% \mathrm{NaCl}$ and adjusting the turbidity of the inoculums to $0.5 \mathrm{McF}$ arland standards at $530 \mathrm{~nm}$ wavelengths (this yields stock suspension of $1-5 \times 10^{6}$ cells $\left.\mathrm{mL}^{-1}\right)$. Working suspension for C. albicans and bacteria was prepared by making $1 / 1000$ and $1 / 100$ dilutions, respectively, with broth media of the stock suspension. After the addition of $0.1 \mathrm{~mL}$ of the C. albicans and bacteria inoculums to the wells, the trays were incubated at $30^{\circ} \mathrm{C}$ for $24 \mathrm{~h}$ in a humid atmosphere. The uninoculated medium was included as a sterility control (blank). Besides growth controls, media with inoculums but without NPs were included. The growth in each well was compared with that of the growth control well. MICs were visually determined and defined as the lowest concentration of NPs that completely inhibited the growth of standard strains of bacteria and C. albicans [8].

\subsection{Determining the Antibiofilm Activity}

2.5.1. Biofilm Preparation and Growth. For biofilm development, C. albicans (CBS 10261) strains were cultured in Sabouraud dextrose agar (Merck, Germany) medium while S. mutans (ATCC35668), S. sobrinus (ATCC27607), and S. salivarius (ATCC9222) were cultured in the brain heart infusion (BHI) (Merck, Germany) agar. After $24 \mathrm{~h}$, one loop of C. albicans and bacteria strains colonies were transferred to $20 \mathrm{~mL}$ Sabouraud dextrose and brain heart infusion broth (Merck, Germany), respectively, and incubated at $30^{\circ} \mathrm{C}$ overnight in an orbital shaker (shaken at $100 \mathrm{rpm}$ ). Candida albicans and bacteria cells were then harvested and washed twice in sterile phosphate-buffered saline (PBS, $0.8 \% \mathrm{w} / \mathrm{v}$ ), sodium chloride $\left(0.02 \%\right.$ w/v, Merck, Germany), $\mathrm{KH}_{2} \mathrm{PO}_{4}$ ( $0.31 \%$ w/v, Merck, Germany), $\mathrm{Na}_{2} \mathrm{HPO}_{4} .12 \mathrm{H}_{2} \mathrm{O}(0.02 \% \mathrm{w} / \mathrm{v}$, Merck, Germany), and $\mathrm{KCl}$ (Panreac, Madrid, Spain). Afterwards, a suspension of respective microorganisms was prepared in RPMI-1640 medium buffered with MOPS [3-(Nmorpholino) propane sulfonic acid]. C. albicans stocks were used to prepare microbial suspension with 0.15 optical densities at $530 \mathrm{~nm}$. This turbidity is equal to $1 \times 10^{5}$ yeasts $\mathrm{mL}^{-1}$. All bacteria suspension with an optical density of 0.1 at $530 \mathrm{~nm}$ was also prepared. This turbidity is equal to $1.5 \times 10^{8} \mathrm{CFU}$ $\mathrm{mL}^{-1}$. Soft denture liner disks containing different concentrations of $\mathrm{CuO}$ NPs were then placed as pairs in sterile 12-well cell culture plates. One $\mathrm{mL}$ of microbial suspension was added to each well; then, the plates were placed at $30^{\circ} \mathrm{C}$ for $48 \mathrm{~h}$ to form a biofilm [26].

2.5.2. Assessing Biofilm Formation. Biofilm formation was assayed by using a 2,3-bis(2-methoxy-4-nitro-5-sulfo-phenyl)-2H-tetrazolium-5-carbox-anilide (XTT, Sigma, USA) reduction assays. XTT was prepared as a saturated solution at a concentration of $0.5 \mathrm{mg} \mathrm{mL}^{-1}$ in Ringer's lactate. This solution was filter-sterilized through a $0.22 \mu \mathrm{m}$ pore size filter, divided into aliquots, and then stored at $-70^{\circ} \mathrm{C}$. Prior to each assay, an aliquot of the XTT stock solution was thawed, and treated with menadione sodium bisulfite (Sigma, USA, $10 \mathrm{mmol} \mathrm{L}^{-1}$ prepared in distilled water) to obtain the final concentration of $1 \mu \mathrm{mol} \mathrm{L} \mathrm{L}^{-1}$ of menadione. After $48 \mathrm{~h}$, the plates were brought out of the incubator, and the contents of each well were emptied. Plates were washed with PBS three times for the unattached microorganisms to be extracted from the plates. In the next phase, acrylic discs were gently transferred to new plates. A $500 \mu \mathrm{L}$ aliquot of XTT-menadione was then added to each pre-washed biofilm and the wells that contained a disk treated with $\mathrm{CuO}$ NPs and incubated for $4 \mathrm{~h}$ at $35^{\circ} \mathrm{C}$ in dark to measure the background XTT levels. Finally, the content of the wells was transferred to another plate and their spectral absorbance at a wavelength of $570 \mathrm{~nm}$ was evaluated by a multi-well scanning spectrophotometer (Polar star omega, Germany). All trials were performed in duplicate to reduce the error rate as much as possible. The well containing soft liner disks and culture medium without microorganism was considered as the negative control and soft liner disks in the wells containing media and organism were used as the positive control [26].

2.6. Statistical Analysis. Statistical analysis was performed using SPSS software (version 11.0) and Mann-Whitney $U$ test was used to compare the microbial biofilm formation between the control and each tested concentrations groups. The quantitative data were presented in terms of mean and standard deviations and $p$ value $<0.05$ was considered as the significance level threshold.

\section{Results}

Characterization of $\mathrm{CuO}$ NPs by SEM analyses confirmed the synthesis of NPs with appropriate structure and size. Figure 1 shows FESEM images recorded from $\mathrm{CuO}$ NPs at different magnifications. The lumps of the particles are observed in the low-magnified image, and at higher magnifications, the adhered NPs of $\mathrm{CuO}$ are observed. A mean diameter of $18.3 \pm 9.1 \mathrm{~nm}(n=50)$ was obtained for NPs.

Antifungal and antimicrobial test results are presented in Table 1. CuO NPs successfully inhibited the growth of the tested standard strains of C. albicans and bacteria at concentrations ranging from 64 to $128 \mu \mathrm{g} \mathrm{mL}^{-1}$ (geometric mean $=84.44 \mu \mathrm{g} \mathrm{mL}^{-1}$ ).

Moreover, biofilm formation of C. albicans (CBS 10261) and Streptococcus spp. in the presence of $\mathrm{CuO}$ NPs with 0.5, 5,50 , and $500 \mu \mathrm{g} \mathrm{mL}^{-1}$ were measured quantitatively by the XTT reduction assay and the results are presented in Table 2.

The results indicated that $\mathrm{CuO}$ NPs exhibited a significant activity in inhibition of microbial biofilm formation in a dose-dependent manner, as reflected by lower absorbance reading when compared with the untreated control. Indeed, the Candida biofilm formation was inhibited by up to $75 \%$ at the concentration of $500 \mu \mathrm{g} \mathrm{mL}^{-1}$ of CuO NPs. The biofilm formation of C. albicans in the presence of $\mathrm{CuO}$ NPs was significantly lower than Streptococcus spp. biofilm formation with a statistically significant difference $(p<0.05)$.

\section{Discussion}

Copper oxide is one of the copper compound families that exhibit useful physical properties, such as high-temperature 


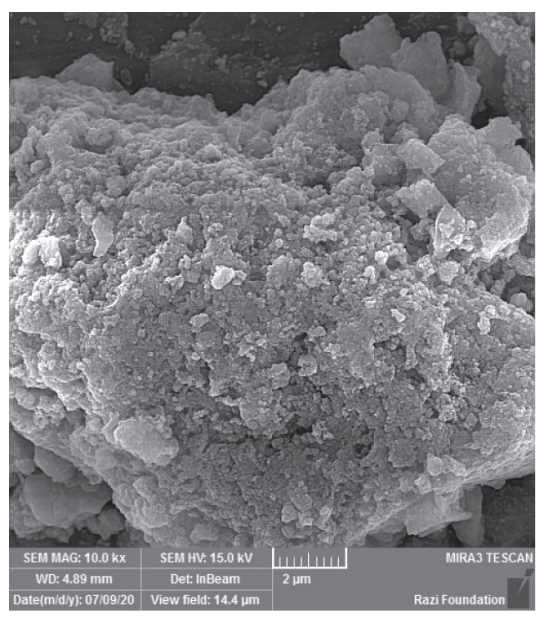

(a)

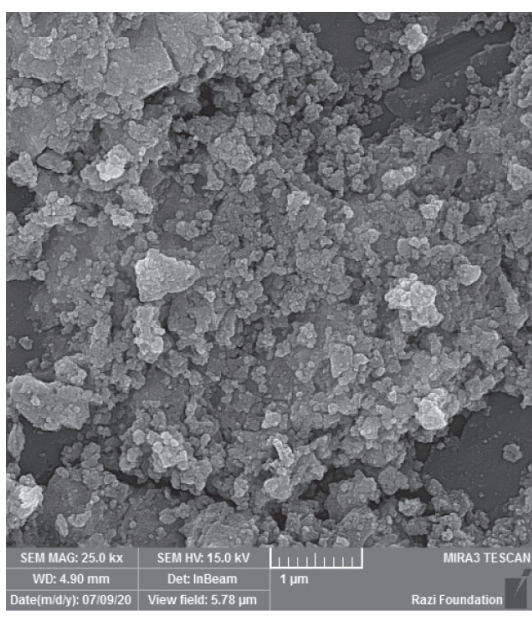

(b)

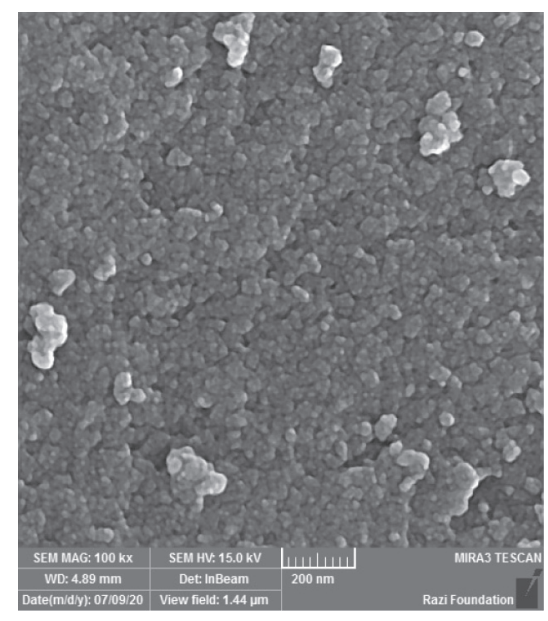

(c)

Figure 1: FESEM images of CuO NPs.

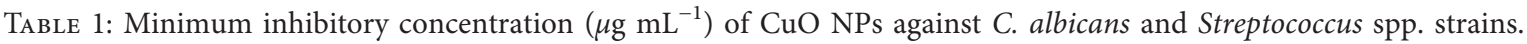

\begin{tabular}{|c|c|c|}
\hline Species & ATCC/CBS & $\operatorname{MIC}\left(\mu \mathrm{g} \mathrm{mL}^{-1}\right)$ \\
\hline C. albicans & C10261 & 64 \\
\hline C. albicans & C1905 & 64 \\
\hline C. albicans & $\mathrm{C} 1912$ & 64 \\
\hline C. albicans & C1949 & 128 \\
\hline C. albicans & $\mathrm{C} 2730$ & 64 \\
\hline S. mutans & A35668 & 128 \\
\hline S. sobrinus & A27607 & 128 \\
\hline S. salivarius & A9222 & 64 \\
\hline
\end{tabular}

Note: MIC: minimal inhibitory concentration; ATCC: American Type Culture Collection; CBS: Centraal Bureau Voor Schimmelcultures.

TABLE 2: Biofilm formation of C. albicans and Streptococcus spp. strains on the soft denture liner disks containing different concentrations of $\mathrm{CuO} \mathrm{NPs}$.

\begin{tabular}{|c|c|c|c|c|c|}
\hline \multirow{2}{*}{ Microbial species } & \multicolumn{5}{|c|}{ Biofilm formation in different concentrations of $\mathrm{CuO}$ NPs $(\%) \pm \mathrm{SD}$} \\
\hline & $0\left(\mu \mathrm{g} \mathrm{mL}^{-1}\right)$ & $0.5\left(\mu \mathrm{g} \mathrm{mL}^{-1}\right)$ & $5.0\left(\mu \mathrm{g} \mathrm{mL}^{-1}\right)$ & $50\left(\mu \mathrm{g} \mathrm{mL}^{-1}\right)$ & $500\left(\mu \mathrm{g} \mathrm{mL}^{-1}\right)$ \\
\hline C. albicans (CBS 10261) & 100 & $87 \pm 5.3$ & $72 \pm 2.9$ & $50 \pm 2.6$ & $25 \pm 2.9$ \\
\hline S. mutans (ATCC35668) & 100 & $95 \pm 4.8$ & $82 \pm 4.1$ & $66 \pm 3.9$ & $70 \pm 6.3$ \\
\hline S. sobrinus (ATCC27607) & 100 & $83 \pm 6.1$ & $75 \pm 5.1$ & $62 \pm 4.1$ & $37 \pm 5.1$ \\
\hline S. salivarius (ATCC9222) & 100 & $90 \pm 3.1$ & $89 \pm 4.6$ & $65 \pm 5.1$ & $40 \pm 4.9$ \\
\hline
\end{tabular}

Note: ATCC: American Type Culture Collection; CBS: Centraal Bureau Voor Schimmelcultures; SD: standard deviation.

superconductivity, electron correlation effects, and spin dynamics. It is relatively cheap, easily mixed with polar liquids and polymers, and comparatively stable in terms of chemical and physical activities. It is notable that the considerable antimicrobial effect of $\mathrm{CuO}$ NPs was achieved in previous studies $[27,28]$.

Intrinsic porosity in the soft denture liners makes them susceptible to be colonized by microorganisms. Microorganisms form a biofilm surface over the prosthesis in contact with oral tissue and may manifest as cracks and irregularities that occur in some stages of soft denture liner preparation. These defects can act as oral reservoirs for adhesion and colonization of microorganisms, which include C. albicans and Streptococcus species particularly, S. mutans, S. sobrinus, and S. salivarius $[29,30]$.
Candida albicans has the most important and predominant oral fungal pathogen. It can adhere and proliferate upon both soft and hard tissue surfaces within the oral cavity, and form biofilm. Streptococcus mutans is a major pathogen of dental caries that can cause significant health problems for denture wearers [26].

Due to some disadvantages of direct use of NPs including the objectionable taste of some additives and the necessity of frequent utilization that needs patient cooperation [31], the purpose of the present study was to assess the antimicrobial and antibiofilm effects of $\mathrm{CuO}$ NPs (in the mean diameter of $18.3 \pm 9.1 \mathrm{~nm}$ ) incorporated into soft denture liners.

In this study, $\mathrm{CuO} \mathrm{NPs}$ inhibited the growth of C. albicans and oral Streptococcus spp. at a geometric means 
of $84.44 \mu \mathrm{g} \mathrm{mL} \mathrm{m}^{-1}$. It is noteworthy that the microbial inhibition efficacy of NPs depends on their concentration as well as their size and shape. Khan et al. found that $\mathrm{CuO}$ NPs at $50 \mu \mathrm{g} \mathrm{mL}^{-1}$ concentration significantly prevented the growth of some oral bacteria [32] and the MIC values of this study were comparable to the present study. Sathiyavimal et al. showed that non-toxic chitosan coated CuO NPs have a good inhibitory effect against specially Gram-negative bacteria rather than Gram-positive ones, at the concentration of $20-80 \mu \mathrm{g} \mathrm{mL}^{-1}$ [24].

In this work, the antibiofilm activity of $\mathrm{CuO}$ NPs exhibited various effects against different microorganisms. In the current study, incorporating the CuO NPs in soft denture liner samples inhibited the biofilm formation of C. albicans and oral Streptococcus species in a dose-dependent manner. The bioactivity and biofilm formation of C. albicans and Streptococcus spp. successively decreased with increasing $\mathrm{CuO}$ NPs concentration by using XTT reduction assays. The MIC and biofilm formation results can probably explain the anti-adhesion and subsequently the antibiofilm effects of $\mathrm{CuO}$ NPs.

In all four concentrations of $0.5,5,50$, and $500 \mu \mathrm{g} \mathrm{mL}^{-1}$ of $\mathrm{CuO}$ NPs that were incorporated in soft denture liners, antibiofilm effects were shown in comparison to the control group, but it was not significant at lower concentrations of 0.5 and $5 \mu \mathrm{g} \mathrm{mL}^{-1}$.

It seems that incorporating $\mathrm{CuO}$ NPs in low concentrations probably does not release and interfere in adhesion and biofilm formation. Based on our findings, there was $75 \%$ C. albicans biofilm inhibition at $500 \mu \mathrm{g} \mathrm{mL}^{-1}$ of $\mathrm{CuO}$ NPs concentration. These findings were in the same line as those of Sivaraj et al. [33].

Among the bacterial species, $S$. sobrinus had the lowest rate $(37 \%)$ of biofilm formation at $500 \mu \mathrm{g} \mathrm{mL} \mathrm{m}^{-1}$ of CuO NPs, while $S$. mutans and $S$. salivarius were less susceptible species to $\mathrm{CuO}$ NPs $(70 \%$ and $40 \%$ biofilm formation at $500 \mu \mathrm{g}$ $\mathrm{mL}^{-1}$, respectively).

The structure of the cell wall plays an important role in the tolerance or susceptibility of the microorganism in the presence of metal NPs. Based on previous findings, Streptococcus strains, as Gram-positive bacteria have a large cell wall, with multiple layers of peptidoglycan, and other protective surface structures $[34,35]$.

Based on the current study, soft denture liner containing $0.5,5$, and $50 \mu \mathrm{g} \mathrm{mL}^{-1} \mathrm{CuO}$ NPs had no significant effect on Streptococcus spp. adhesion and, subsequently, biofilm formation ( $p$ value $>0.05$ ). These findings were in contrast with Eshed et al. study, indicating that $\mathrm{CuO}$ NPs at low concentration prevented the biofilm formation of $S$. mutans [36]. The possible explanation for these differences may be related to biofilm formation assay. In the present study, the XTT method was used as a quantitative measurement of biofilm formation.

The results of this microbial assay confirmed that the susceptibility of C. albicans to CuO NPs of the soft denture liner samples was more than oral Streptococcus strains. These findings were consistent with Méndez-Serrano's study [37].

In another study, the evaluation of candidal biofilm formation on the teeth coated with $\mathrm{CuO}$ NPs revealed the reduction of biofilm formation by $70 \%$ which is in line with the result of the present study [36]. In a study by Pugazhendhi et al., it was shown that $\mathrm{Fe}$ doped $\mathrm{CuO}$ has a very good antimicrobial and antibiofilm activity against $S$. aureus, S. epidermidis, and C. albicans. Due to its cationic nature, it would have promoted an easy binding and penetration, which leads to a fungicidal activity [38].

As revealed in another study, coated brackets with metal NPs showed dramatic antimicrobial and antibiofilm effects in comparison with the control groups [21]. The antimicrobial mechanisms of $\mathrm{CuO}$ NPs may be related to microbial cell wall attachment, and cause structural changes, which then provokes intracellular oxidative stress. Consequently, they reduce the vital activity of the microbial cell such as permeability, which then results in less biofilm formation activity and eventually leads to the death of the pathogens.

In a study, Tabrez Khan et al. found that $50 \mu \mathrm{g} \mathrm{mL}^{-1}$ of $\mathrm{CuO}$ NPs $(40 \mathrm{~nm})$ prevented the growth of some oral bacteria [39]. The MIC values of this study were comparable to ours, although the size of our NPs was smaller $(18 \mathrm{~nm})$ than theirs.

Further studies are recommended to assess the biocompatibility and mechanical properties of denture liners containing $\mathrm{CuO}$ NPs, especially at MIC concentration. The stability and duration of the effectiveness of denture liners containing $\mathrm{CuO}$ NPs should be assessed. It is also suggested that the mechanism of antimicrobial effect of $\mathrm{CuO}$ NPs in different strains of fungi and bacteria should be evaluated in the future.

\section{Conclusion}

It was concluded that the $\mathrm{CuO}$ NPs incorporated soft denture liner is an efficient, practical, and accessible alternative for denture users with an oral microbial infection. The $\mathrm{CuO}$ NPs might have the potential as a microbial resistant coating in biomedical devices and limit the spread of some pathogenic microbes.

\section{Data Availability}

All the data used to support the findings of this study are available from the corresponding author upon request.

\section{Additional Points}

Scientific rationale for study: the use of soft denture liners is associated with several problems such as difficulty in cleaning, microbial colonization, and subsequently caused denture stomatitis. In old patients, cleansing procedures are challenging and make soft liners susceptible to plaque accumulation. To reduce this problem, several solutions such as adding NPs have been suggested. Principal findings: $\mathrm{CuO}$ NPs caused a significant reduction of microbial growth and incorporation of these NPs in soft denture liner decreased biofilm formation. Practical implications: the soft denture liner with $\mathrm{CuO}$ NPs is proposed as an appropriate carrier for the prevention of denture stomatitis and improves their properties. 


\section{Conflicts of Interest}

The authors declare that they have no conflicts of interest regarding the publication of this paper.

\section{Authors' Contributions}

K. Z. and E. A. conceived the ideas; N. S and H. H collected the data; Z. Z and E. A. analyzed the data; and K. Z., E. A., and $Z$. Z. led the writing.

\section{Acknowledgments}

This study was financially supported by the Vice-Chancellor for Research of Shiraz University of Medical Sciences (Grant Agreement No. 11571). The authors wish to thank Dr. Nasrin Shokrpour at the Research Consultation Center (RCC) of Shiraz University of Medical Sciences for his invaluable assistance in editing this manuscript.

\section{References}

[1] H. S. A. Alshakaki and H. A. Al-Essa, "A comparative evaluation of shear bond strength between self-cured resilient liner and denture base resin with different surface treatments," International Journal of Applied Dental Sciences, vol. 6, 2020.

[2] C. B. Melo, "Effect of a continuous mechanical polishing protocol on the color stainability microhardness mass and surface roughness of denture base acrylic resin," The Journal of Prosthetic Dentistry, in Press, 2020.

[3] S. An, "Incorporation of antimicrobial agents in denture base resin: a systematic review," The Journal of Prosthetic Dentistry, 2020, in Press.

[4] A. Fallah-tafti, "Stability and duration of antifungal effects of Nystatin and Fluconazole mixed with a tissue conditioner on colonization of Candida Albicans (in vitro)," Journal of Research in Dental Sciences, vol. 11, no. 1, pp. 21-26, 2014.

[5] K. M. Lyons, R. D. Cannon, J. Beumer, M. M. Bakr, and R. M. Love, "The role of biofilms and material surface characteristics in microbial adhesion to maxillary obturator materials: a literature review," The Cleft Palate-Craniofacial Journal, vol. 57, no. 4, pp. 487-498, 2020.

[6] K. R. Pachava, L. K Nadendla, L. S Alluri, H Tahseen, and N. P Sajja, "Invitro antifungal evaluation of denture soft liner incorporated with tea tree oil: a new therapeutic approach towards denture stomatitis," Journal of Clinical and Diagnostic Research: JCDR, vol. 9, no. 6, pp. ZC62-4, 2015.

[7] L. Karygianni, "Biofilm matrixome: extracellular components in structured microbial communities," Trends in Microbiology, vol. 28, no. 8, pp. 668-681, 2020.

[8] Z. Zareshahrabadi, "Morphogenesis and pathogenesis regulation of Candida albicans by probiotic bacterium - pediococcus acidilactici," Journal of Microbiology, Biotechnology and Food Sciences, vol. 10, no. 1, pp. 5-11, 2020.

[9] M. Mundathaje, "Redefining treatment for denture stomnatitis-a review," International Journal of Research In Dentistry, vol. 4, no. 2, pp. 8-20, 2014.

[10] M. I. Issa and N. Abdul-Fattah, "Evaluating the effect of silver nanoparticles incorporation on antifungal activity and some properties of soft denture lining material," Journal of Baghdad College of Dentistry, vol. 325, no. 2219, pp. 1-15, 2015.
[11] F. Mahboub, F. Salehsaber, F. Parnia, V. Gharekhani, Y. Kananizadeh, and M. Taghizadeh, "Effect of denture cleansing agents on tensile and shear bond strengths of soft liners to acrylic denture base," Journal of Dental Research, Dental Clinics, Dental Prospects, vol. 11, no. 3, pp. 183-188, 2017.

[12] H. S. Mohammed, S Singh, P. A Hari et al., "Evaluate the effect of commercially available denture cleansers on surface hardness and roughness of denture liners at various time intervals," International Journal of Biomedical Science: IJBS, vol. 12, no. 4, pp. 130-142, 2016.

[13] V. T. Noronha, A. J. Paula, G. Durán et al., "Silver nanoparticles in dentistry," Dental Materials, vol. 33, no. 10, pp. 1110-1126, 2017.

[14] Z. Yang, L. Han, Y. Guo, L. Jia, C. Yin, and Y. Xia, "Nanotechnology in dental therapy and oral tissue regeneration,"in Nanotechnology in Regenerative Medicine and Drug Delivery Therapy, Springer, Singapore, pp. 91-189, 2020.

[15] J. A. Skupien, F. Valentini, N. Boscato, and T. Pereira-Cenci, "Prevention and treatment of Candida colonization on denture liners: a systematic review," The Journal of Prosthetic Dentistry, vol. 110, no. 5, pp. 356-362, 2013.

[16] S. Sathiyavimal, S. Vasantharaj, V. Veeramani et al., "Green chemistry route of biosynthesized copper oxide nanoparticles using Psidium guajava leaf extract and their antibacterial activity and effective removal of industrial dyes," Journal of Environmental Chemical Engineering, vol. 9, no. 2, Article ID 105033, 2021.

[17] V. M. Urban, T. F. Lima, M. G. Bueno et al., "Effect of the addition of antimicrobial agents on shore A hardness and roughness of soft lining materials," Journal of Prosthodontics, vol. 24, no. 3, pp. 207-214, 2015.

[18] L. K. Foong, M. M. Foroughi, A. F. Mirhosseini et al., "Applications of nano-materials in diverse dentistry regimes," Rsc Advances, vol. 10, no. 26, pp. 15430-15460, 2020.

[19] S. R. D’Mello, C. N. Cruz, M.-L. Chen, M. Kapoor, S. L. Lee, and K. M. Tyner, "The evolving landscape of drug products containing nanomaterials in the United States," Nature Nanotechnology, vol. 12, no. 6, pp. 523-529, 2017.

[20] A. A. Alswat, M. B. Ahmad, M. Z. Hussein, N. A. Ibrahim, and T. A. Saleh, "Copper oxide nanoparticles-loaded zeolite and its characteristics and antibacterial activities," Journal of Materials Science \& Technology, vol. 33, no. 8, pp. 889-896, 2017.

[21] B. Ramazanzadeh, A Jahanbin, M Yaghoubi et al., "Comparison of antibacterial effects of $\mathrm{ZnO}$ and $\mathrm{CuO}$ nanoparticles coated brackets against Streptococcus mutans," Journal of Dentistry (Shiraz, Iran), vol. 16, no. 3, pp. 200-5, 2015.

[22] K. Ginjupalli, R. Alla, T. Shaw, C. Tellapragada, L. Kumar Gupta, and P. Nagaraja Upadhya, "Comparative evaluation of efficacy of Zinc oxide and Copper oxide nanoparticles as antimicrobial additives in alginate impression materials," Materials Today: Proceedings, vol. 5, no. 8, pp. 16258-16266, 2018.

[23] S. Sathiyavimal, S. Vasantharaj, D. Bharathi et al., "Biogenesis of copper oxide nanoparticles (CuONPs) using Sida acuta and their incorporation over cotton fabrics to prevent the pathogenicity of Gram negative and Gram positive bacteria," Journal of Photochemistry and Photobiology B: Biology, vol. 188, pp. 126-134, 2018.

[24] S. Sathiyavimal, S. Vasantharaj, T. Kaliannan, and A. Pugazhendhi, "Eco-biocompatibility of chitosan coated biosynthesized copper oxide nanocomposite for enhanced industrial (Azo) dye removal from aqueous solution and 
antibacterial properties," Carbohydrate Polymers, vol. 241, Article ID 116243, 2020.

[25] S. Vasantharaj, S. Sathiyavimal, M. Saravanan et al., "Synthesis of ecofriendly copper oxide nanoparticles for fabrication over textile fabrics: characterization of antibacterial activity and dye degradation potential," Journal of Photochemistry and Photobiology B: Biology, vol. 191, pp. 143-149, 2019.

[26] A. Azad, "Protective effects of the probiotic bacterium Streptococcus thermophilus on Candida albicans morphogenesis and a murine model of oral candidiasis," Iranian Journal of Medical Sciences, vol. 46, no. 3, pp. 207-217, 2020.

[27] M. I. Din, "Single step green synthesis of stable copper oxide nanoparticles as efficient photo catalyst material," Biomedical Materials, vol. 9, pp. 41-48, 2017.

[28] P. G. Bhavyasree and T. S. Xavier, "Green synthesis of Copper Oxide/Carbon nanocomposites using the leaf extract of Adhatoda vasica Nees, their characterization and antimicrobial activity," Heliyon, vol. 6, no. 2, Article ID e03323, 2020.

[29] M. I. A. Arbeláeza, "Long-term effect of daily chemical disinfection on surface topography and Candida albicans biofilm formation on denture base and reline acrylic resins," Oral Health and Preventive Dentistry, vol. 18, pp. 999-1010, 2020.

[30] J. B. Pinheiro, M. P. Vomero, C. do Nascimento et al., "Genomic identification of microbial species adhering to maxillofacial prostheses and susceptibility to different hygiene protocols," Biofouling, vol. 34, no. 1, pp. 15-25, 2018.

[31] R. K. Alla, "Evaluation of the antimicrobial activity of heatcure denture base resin materials incorporated with silver nanoparticles," International Journal of Dental Materials, vol. 1, 2019.

[32] M. Ahamed, "Synthesis characterization and antimicrobial activity of copper oxide nanoparticles," Journal of Nanomaterials, vol. 2014, Article ID 637858, 4 pages, 2014.

[33] R. Sivaraj, P. K. S. M. Rahman, P. Rajiv, S. Narendhran, and R. Venckatesh, "Biosynthesis and characterization of Acalypha indica mediated copper oxide nanoparticles and evaluation of its antimicrobial and anticancer activity," Spectrochimica Acta Part A: Molecular and Biomolecular Spectroscopy, vol. 129, pp. 255-258, 2014.

[34] H. M. Yusof, R. Mohamad, and U. H. Zaidan, "Microbial synthesis of zinc oxide nanoparticles and their potential application as an antimicrobial agent and a feed supplement in animal industry: a review," Journal of Animal Science and Biotechnology, vol. 10, no. 1, pp. 1-22, 2019.

[35] L. Pasquina-Lemonche, J. Burns, R. D. Turner et al., "The architecture of the gram-positive bacterial cell wall," Nature, vol. 582, no. 7811, pp. 294-297, 2020.

[36] M. Eshed, J. Lellouche, S. Matalon, A. Gedanken, and E. Banin, "Sonochemical coatings of $\mathrm{ZnO}$ and $\mathrm{CuO}$ nanoparticles inhibit Streptococcus mutans biofilm formation on teeth model," Langmuir, vol. 28, no. 33, pp. 12288-12295, 2012.

[37] J. Méndez-Serrano, "Adhesion of Candida albicans and Streptococcus mutans to silver nanoparticle-modified polymethylmethacrylate," Interciencia, vol. 45, no. 1, pp. 23-27, 2020.

[38] A. Pugazhendhi, S. S. Kumar, M. Manikandan, and M. Saravanan, "Photocatalytic properties and antimicrobial efficacy of Fe doped $\mathrm{CuO}$ nanoparticles against the pathogenic bacteria and fungi," Microbial Pathogenesis, vol. 122, pp. 84-89, 2018.

[39] S. Tabrez Khan, M. Ahamed, A. Al-Khedhairy, and J. Musarrat, "Biocidal effect of copper and zinc oxide nanoparticles on human oral microbiome and biofilm formation," Materials Letters, vol. 97, pp. 67-70, 2013. 